\title{
Comparative clinicopathological and outcome analysis of differentiated thyroid cancer in Saudi patients aged below 60 years and above 60 years
}

This article was published in the following Dove Press journal:

Clinical Interventions in Aging

29 August 2016

Number of times this article has been viewed

\author{
Khalid Hussain AL-Qahtani' \\ Mutahir A Tunio² \\ Mushabbab Al Asiri \\ Yasser Bayoumi ${ }^{3}$ \\ Ali Balbaid ${ }^{2}$ \\ Naji J Aljohani ${ }^{4}$ \\ Hanadi Fatani ${ }^{5}$ \\ 'Department of Otolaryngology- \\ Head \& Neck Surgery, College of \\ Medicine, King Saud University, \\ Riyadh, Saudi Arabia; ${ }^{2}$ Department of \\ Radiation Oncology, Comprehensive \\ Cancer Center, King Fahad \\ Medical City, Riyadh, Saudi Arabia; \\ ${ }^{3}$ Department of Radiation Oncology, \\ $\mathrm{NCl}$, Cairo University, Cairo, Egypt; \\ ${ }^{4}$ Department of Endocrinology and \\ Thyroid Oncology, ${ }^{5}$ Histopathology, \\ Comprehensive Cancer Center, King \\ Fahad Medical City, Riyadh, Saudi \\ Arabia
}

Introduction: The aim of this study was to evaluate the treatment outcomes of differentiated thyroid cancer in Saudi patients aged above 60 years.

Materials and methods: Comparative analysis was performed in 252 patients aged 46-60 years (Group A) and 118 patients aged above 60 years (Group B), who had thyroidectomy, radioactive iodine-131, and thyroid-stimulating hormone suppression therapy between July 2000 and December 2012. Different clinicopathological features, treatment, complications, disease-free survival, and overall survival rates were compared.

Results: Mean age of patients in Group A was 51.9 years (range: 46-60), and mean age of those in Group B was 68.6 years (range: 62-97). Group B patients had higher positive lymph nodes (43.2\%), $P=0.011$. The frequency of extrathyroidal extension, multifocality, and lymphovascular space invasion was seen more in Group B than in Group A. Postsurgical complications (permanent hypoparathyroidism, bleeding, and wound infections) were also seen more in Group B ( $P=0.043, P=0.011$, and $P=0.021$, respectively). Group B patients experienced more locoregional recurrences $(11.0 \%, P=0.025)$; similarly, more distant metastases were observed in Group B $(15.3 \%, P=0.003)$. The 10-year disease-free survival rates were $87.6 \%$ in Group A and $70.8 \%$ in Group B $(P<0.0001)$.

Conclusion: Differentiated thyroid cancer in patients aged above 60 years are more aggressive biologically and associated with a worse prognosis, and the morbidity is significantly high as compared to patients aged below 60 years.

Keywords: differentiated thyroid cancers, patients aged above 45 years, aged above 60 years, clinicopathological characteristics, treatment outcomes, elderly patients, aged below 60 years, comparative analysis

\section{Introduction}

The incidence of differentiated thyroid cancers (DTCs), including papillary thyroid cancer (PTC) and follicular thyroid cancer variants, is rising significantly globally over the past decades, with a wide geographic variation. ${ }^{1}$ In Saudi Arabia, DTC is the second-most common malignancy, accounting for more than $10 \%$ of all cancers among middle-aged women. ${ }^{2}$ Generally, age above 45 years is regarded as a poor prognostic marker in DTC, using the American Joint Cancer Committee/Union Internationale Contre le Cancer Tumor Nodes Metastasis staging system; the mortality rate climbs gradually starting at age 45 years and above., ${ }^{3,4}$ DTC in older patients ( $>60$ years) has some distinctive clinicopathological features: 1) large size of primary tumors at the time of diagnosis; 2) high risk of distant metastases at the time of presentation; 3) more aggressive histopathological variants of DTC; and 4) higher recurrence rates. 5,6
Correspondence: Mutahir A Tunio Department of Radiation Oncology, Comprehensive Cancer Center, King Fahad Medical City, Riyadh II525, Saudi Arabia

Tel +966 II 2889999

Fax +966 I| 2889999

Email drmutahirtonio@hotmail.com (c)
hereby accept the Terms. Non-commercial uses of the work are permitted without any further permission from Dove Medical Press Limited, provided the work is properly attributed. For permission hereby accept the Terms. Non-commercial uses of the work are permitted without any further permission from Dove Mediect
for commercial use of this work, please see paragraphs 4.2 and 5 of our Terms (https://www.dovepress.com/terms.php). 
The management of DTC in older patients remains controversial as there has been conflicting literature in regard to approach. ${ }^{7}$ DTC in older patients is treated in a similar way as that in young adults, primarily because of scarcity of clinical and outcome data. ${ }^{8}$

In the present study, we aimed to evaluate the difference between different clinicopathological characteristics, and treatment outcomes of DTC in Saudi patients aged $<60$ years and $>60$ years.

\section{Methods}

After a formal approval from the Institutional ethical committee of King Fahad Medical City and formal written consent from patients, medical records of 1,192 patients with confirmed DTC, who were managed in our institute during the period of 2000 and 2012, were retrieved using computer-based database system. As 45 years of age has been used as a cutoff in the staging of DTC in most of studies, the patients aged below 45 years were excluded. ${ }^{9}$ Patients with incomplete information and those lost at follow-up were also excluded. Patients for analysis were retrieved in the following manner.

\section{Grouping}

All patients were divided in two groups: 1) Group A: patients aged above 45 years but below 60 years, and 2) Group B: patients aged above 60 years.

\section{Clinical variables}

Descriptive data (age, sex, and symptoms, histology, size of primary tumor, variants, multifocality, lymphovascular invasion, staging, surgery types, neck dissection, adjuvant treatment and doses in millicurie [mCi], radiation therapy) were collected for each patient. Radiological data were collected from different imaging modalities (neck ultrasonography, whole body scan, computed tomography, fluoro-deoxyglucose positron emission tomography-computed tomography).

\section{Statistical analysis}

The primary objective of this study was the disease-free survival (DFS) in elderly population, while secondary objectives were locoregional control (LRC), distant metastasis control (DMC), and overall survival (OS) rates.

Locoregional recurrence (LR) was defined as the gap between the surgery date and the date of radiologically detectable disease in the thyroid bed or in cervical lymph nodes on imaging in the presence of elevated thyroglobulin levels. Distant metastasis (DM) was defined as the gap between the surgery date and the date of documented disease outside the neck on imaging. DFS was described as the gap between the surgery date and the date of documented all-site relapse (LR and DM) or last follow-up (censored). OS was defined as the gap between the surgery date and the date of death or last follow-up (censored).

To determine the differences in various clinical variables, chi-square or Student's $t$-tests were used. $P$-value $<0.05$ was considered statistically significant. All graphs were drawn with the Kaplan-Meier method, and the comparisons for various survival curves were performed with the log-rank test. All data analyses were done using SPSS version 16.0 (SPSS Inc., Chicago, IL, USA).

\section{Results Clinical variables}

Among the 1,192 registered DTC patients in our department, 252 adults (21.2\%) aged below 60 years (Group A) and 118 (9.9\%) aged above 60 years (Group B) were found to have DTC. The clinical, diagnostic, and therapeutic characteristics of both groups are described in Table 1. The mean age of study cohort at diagnosis was 57.2 years (range: 46-97). The study cohort $(n=370)$ consisted of $292(78.9 \%)$ females and $78(21.1 \%)$ males. The predominant histopathology was PTC (93\%). Classic variant PTC was more frequent in Group A (63.4\%), whereas follicular variant PTC was more common $40.2 \%$ in Group B $(P=0.002)$. The mean size of the primary tumor was $2.8 \mathrm{~cm}$ (range: $0.3-11$ ), with no significant difference between Groups A and B $(P=0.653)$. Pathologically involved cervical lymph nodes were seen more in elderly patients $(51 \%, P=0.002)$. In Group B, distant metastases at the time of diagnosis were nearly three times more than that in Group A $(P=0.010)$. Other features (extrathyroidal extension, multifocality, and lymphovascular space invasion) were significantly high in Group B $(P=0.018, P=0.006$, and $P=0.003$, respectively).

All patients were treated with total or near-total thyroidectomy. However, the frequency of neck dissection was seen more in Group A than in Group B $(P=0.027)$. A total of 326 patients $(88.1 \%)$ were treated with adjuvant radioactive iodine-131 (RAI) ablation with a median gap of 8.2 weeks (6.8-16.6 weeks) from the date of surgery.

\section{Toxicity profile}

Postsurgical complication rates including permanent hypocalcemia, postoperative bleeding, and wound infection were much higher in Group B as compared to Group A (Table 2). Similarly, acute and delayed (any grade) toxicities of adjuvant RAI were significantly higher in Group B than in Group A. 
Table I Comparison of clinicopathological and treatment characteristics of patients with differentiated thyroid carcinoma aged below 60 years and above 60 years at presentation

\begin{tabular}{|c|c|c|c|}
\hline Variables & Aged below 60 years $(n=252)$ & Aged above 60 years $(n=\mid 18)$ & $P$-value \\
\hline \multicolumn{4}{|l|}{ Age (years) } \\
\hline Median (range) SD & $51.9(46-60) \pm 4.2$ & $68.6(62-97) \pm 565.2$ & 0.022 \\
\hline \multicolumn{4}{|l|}{ Sex, n (\%) } \\
\hline$M$ & $50(19.8)$ & $28(12.3)$ & \\
\hline $\mathrm{F}$ & $202(74.1)$ & $90(87.7)$ & 0.235 \\
\hline \multicolumn{4}{|l|}{ Tumor size $(\mathrm{cm})$} \\
\hline Median (range) SD & $2.92(0.3-11) \pm 1.97$ & $2.88(0.2-10) \pm 1.87$ & 0.653 \\
\hline \multicolumn{4}{|l|}{ Histology, n (\%) } \\
\hline Papillary & $235(93.3)$ & $109(92.4)$ & 0.063 \\
\hline Classic & $149(63.4)$ & $46(42.2)$ & 0.003 \\
\hline Follicular & $63(26.8)$ & $44(40.2)$ & 0.002 \\
\hline Tall cell & $18(7.6)$ & $13(11.9)$ & 0.041 \\
\hline Sclerosing & $5(2.2)$ & $6(5.5)$ & 0.044 \\
\hline Follicular & $17(6.7)$ & $9(7.6)$ & 0.065 \\
\hline \multicolumn{4}{|l|}{ T stage, $\mathrm{n}(\%)$} \\
\hline$T_{1}$ & $70(27.8)$ & $28(23.7)$ & \\
\hline$T_{2}$ & $106(42.1)$ & $36(30.5)$ & 0.018 \\
\hline $\mathrm{T}_{3}^{2}$ & $62(24.5)$ & $47(39.9)$ & \\
\hline $\mathrm{T}_{4}$ & $14(5.6)$ & $7(5.9)$ & \\
\hline \multicolumn{4}{|l|}{ N stage, n (\%) } \\
\hline $\mathrm{N}_{0}$ & $184(73.1)$ & $67(56.9)$ & \\
\hline$N_{1}$ & $68(26.9)$ & $51(43.2)$ & 0.002 \\
\hline $\mathrm{N}_{\mathrm{la}}$ & $30(44.2)$ & $30(58.8)$ & \\
\hline $\mathrm{N}_{\mathrm{Ib}}$ & $38(55.8)$ & $21(41.2)$ & \\
\hline \multicolumn{4}{|l|}{ M stage, n (\%) } \\
\hline$M_{0}$ & $242(96.0)$ & $105(88.9)$ & 0.010 \\
\hline$M_{1}$ & $10(4.0)$ & $13(11.0)$ & \\
\hline \multicolumn{4}{|l|}{ Multifocality, n (\%) } \\
\hline Yes & $76(30.2)$ & $52(44.1)$ & 0.006 \\
\hline No & $176(69.8)$ & $66(55.9)$ & \\
\hline \multicolumn{4}{|l|}{ LVSI, n (\%) } \\
\hline Yes & $63(25.0)$ & $48(40.7)$ & 0.003 \\
\hline No & $189(75.0)$ & $70(59.3)$ & \\
\hline \multicolumn{4}{|l|}{ Surgery, n (\%) } \\
\hline Total thyroidectomy & $215(85.3)$ & $99(83.9)$ & \\
\hline Near total thyroidectomy & $37(14.7)$ & $19(16.1)$ & 0.065 \\
\hline \multicolumn{4}{|l|}{ Neck dissection, n (\%) } \\
\hline No & $46(18.2)$ & $38(32.2)$ & \\
\hline Yes & $206(81.7)$ & $80(67.8)$ & 0.027 \\
\hline Central & $104(50.5)$ & $48(60.0)$ & \\
\hline Lateral & $102(49.5)$ & $32(40.0)$ & \\
\hline \multicolumn{4}{|l|}{ Adjuvant RAI therapy, $\mathrm{n}(\%)$} \\
\hline No & 35 (13.9) & $9(6.9)$ & \\
\hline Yes & $217(84.9)$ & $109(89.8)$ & 0.460 \\
\hline $30 \mathrm{mCi}$ & $4 \mid(18.9)$ & $15(13.7)$ & \\
\hline $100 \mathrm{mCi}$ & $48(22.1)$ & $21(19.3)$ & \\
\hline $150 \mathrm{mCi}$ & $117(53.9)$ & $58(53.3)$ & \\
\hline $200 \mathrm{mCi}$ & II (5.I) & $15(13.7)$ & \\
\hline
\end{tabular}

Note: Data in bold indicates statistical significance.

Abbreviations: n, number; DTC, differentiated thyroid cancer; SD, standard deviation; M, male; F, female; T, tumor; N, node; M, metastasis; LVSI, lymphovascular space invasion; $\mathrm{RAl}$, radioactive iodine; $\mathrm{mCi}$, millicurie.

\section{Outcomes}

The median follow-up period was 5.5 years (range: $0.7-10.4$ ).

For all patients, the estimated 10-year LRC and DMC rates were $91.8 \%$ and $89.6 \%$, respectively. Group B was associated with inferior 10-year LRC and DMC rates (86.0\% and $82.2 \%$, respectively) than those in Group A (94.3\% and 93.1\%, respectively). A total of $25 \mathrm{LRs}$ (6.8\%) were observed: 12/252 in Group A and 13/118 in Group B ( $P=0.025)$ (Table 3). The LRs were managed by surgery (lateral neck exploration, 13 patients; completion thyroidectomy, five patients; excision, two patients), neck irradiation (three patients), and RAI ablation (16 patients). A total of 32 patients developed 
Table 2 Comparative analysis of complications of surgery and toxicities of radioactive iodine ablation in our cohort

\begin{tabular}{|c|c|c|c|}
\hline Toxicity & $\begin{array}{l}\text { Aged below } 60 \text { years } \\
(n=252)\end{array}$ & $\begin{array}{l}\text { Aged above } 60 \text { years } \\
(n=|| 8)\end{array}$ & $P$-value \\
\hline \multicolumn{4}{|l|}{ Thyroidectomy, n (\%) } \\
\hline Hypoparathyroidism & $35(15.2)$ & $28(23.7)$ & 0.042 \\
\hline Transient & $34(97.2)$ & $26(92.9)$ & \\
\hline Permanent & $\mathrm{I}(2.8)$ & $2(7.1)$ & 0.043 \\
\hline Recurrent laryngeal nerve damage & $3(1.2)$ & $2(1.7)$ & 0.071 \\
\hline Postoperative hemorrhage & $4(1.6)$ & $8(6.8)$ & 0.011 \\
\hline Wound infection & $2(0.8)$ & $3(2.5)$ & 0.021 \\
\hline \multicolumn{4}{|l|}{ RAl ablation, n (\%) } \\
\hline Acute & $88(34.9)$ & $42(35.6)$ & 0.061 \\
\hline Sialadenitis & $25(28.4)$ & $15(35.7)$ & 0.042 \\
\hline Acute sickness (nausea and vomiting) & $21(23.8)$ & $10(23.8)$ & 0.054 \\
\hline Severe hair loss & $23(26.2)$ & $8(19.1)$ & 0.064 \\
\hline Neck pain & $19(21.6)$ & $9(21.4)$ & 0.072 \\
\hline RAl induced hyponatremia & 0 & $2(1.7)$ & 0.010 \\
\hline \multicolumn{4}{|l|}{ RAl ablation, n (\%) } \\
\hline Late & II (4.3) & $9(7.6)$ & 0.034 \\
\hline Sicca syndrome & $3(27.3)$ & $4(44.4)$ & \\
\hline Nasolacrimal duct obstruction & $7(63.6)$ & $4(44.4)$ & \\
\hline Second malignancy & 0 & 0 & \\
\hline Infertility & 0 & 0 & \\
\hline Lung fibrosis & I (9.1) & I (II.2) & \\
\hline
\end{tabular}

Note: Data in bold indicates statistical significance.

Abbreviations: $n$, number; RAl, radioactive iodine.

DM (8.7\%): 14/252 in Group A and 18/118 in Group B $(P=0.003)$. DMs were treated with RAI ablation (28 patients) and palliative radiotherapy (three patients). In addition, four patients were salvaged with targeted therapy. The projected 10 -year DFS rates were $87.6 \%$ in Group A and $70.8 \%$ in Group B $(P<0.0001$; Figure 1). The estimated 10-year OS rates in both groups were found similar $(P=0.491)$. Furthermore, in a multivariate analysis of Group B patients, positive lymph nodes $(P<0.0001)$ and partial response after first RAI ablation $(P<0.002)$ were found to be important independent prognostic factors predicting DFS.

\section{Discussion}

Recent data have shown that the DFS rate in DTC declines gradually with each 5 -year increment in age above 45 years. ${ }^{3}$ However, the literature regarding clinicopathological features and treatment outcomes in elderly patients remains scarce and controversial, which is likely attributed to the definition of "elderly" itself. ${ }^{5-8}$ Because of the lack of definition for "elderly", different studies have used different age limits for elderly patients; few of them have reported it around 80 years. ${ }^{7,10,11}$ For the purpose of the present study, we defined "elderly" as patients aged above 60 years for threefold

Table 3 Pattern of failure after thyroidectomy and radioactive iodine therapy in patients with differentiated thyroid cancer aged below 60 years and above 60 years

\begin{tabular}{|c|c|c|c|}
\hline Failures & $\begin{array}{l}\text { Aged below } 60 \text { years } \\
(n=252)\end{array}$ & $\begin{array}{l}\text { Aged above } 60 \text { years } \\
(n=I \mid 8)\end{array}$ & $P$-value \\
\hline Locoregional, n (\%) & $12(4.8)$ & $13(11.0)$ & 0.025 \\
\hline Thyroid bed & $3(25.0)$ & $4(30.7)$ & \\
\hline Lymph nodes & $9(75.0)$ & $9(69.3)$ & \\
\hline Distant, n (\%) & $14(5.6)$ & $18(115.3)$ & 0.003 \\
\hline Lungs & II (78.6) & $13(72.2)$ & \\
\hline Bones & $3(21.4)$ & $3(16.7)$ & \\
\hline Brain & 0 & $2(I I .1)$ & \\
\hline Locoregional + distant, n (\%) & $7(2.8)$ & II (9.3) & 0.031 \\
\hline 10-year LRC rate & $94.3 \%$ & $86.0 \%$ & 0.019 \\
\hline 10-year DMC rate & $93.1 \%$ & $82.2 \%$ & 0.001 \\
\hline 10-year OS rate & $96.7 \%$ & $91.0 \%$ & 0.491 \\
\hline
\end{tabular}

Abbreviations: $n$, number; LRC, locoregional control; DMC, distant metastasis control; OS, overall survival. 


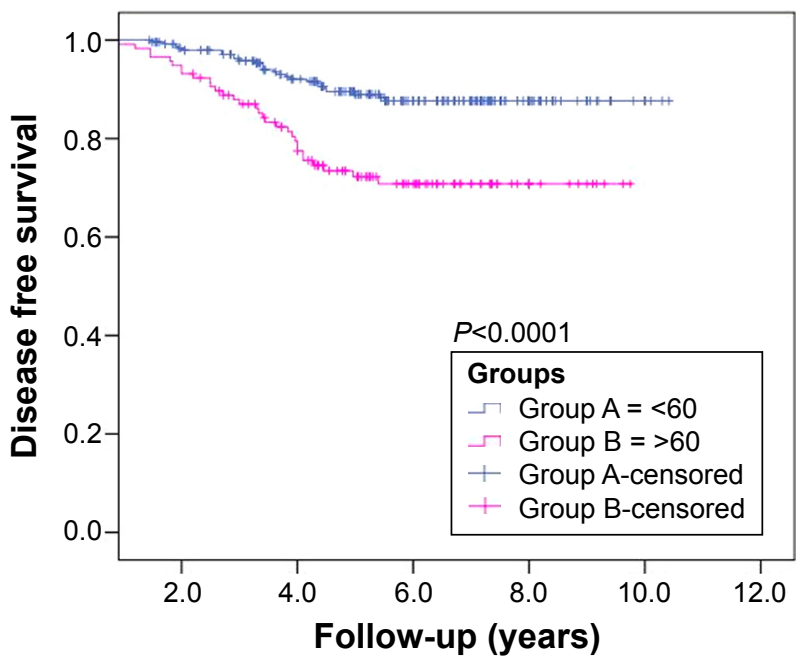

Figure I Cumulative disease-free survival probability of patients with differentiated thyroid cancer aged $<60$ years and $>60$ years.

reasons; 1) according to the Saudi Arabia Population Census 2004 , only $3.5 \%$ of population is above 65 years; ${ }^{12} 2$ ) thus by decreasing the age limit to 60 years, we achieved a large sample size; 3) which was also in agreement with other previously published data. ${ }^{13}$

In the present study, no significant difference was observed in primary tumor volumes between the two age groups, which is consistent with the reported literature. ${ }^{14}$ In contrast to patients aged below 60 years, the pathological positive neck nodes were significantly higher in patients aged above 60 years, owing to the presence of lymphovascular space invasion, multifocality, and aggressive histopathological variants in elderly patients, which supports the routine use of lateral neck dissection in this age group. ${ }^{15,16}$

In contrast to the study by Tartaglia et al, ${ }^{17}$ patients aged above 60 years experienced significant postoperative hypoparathyroidism, hemorrhage, and wound infections. This observation favors the hypothesis of lobectomy/hemithyroidectomy for primary tumor in this age group, especially in patients with more than one associated comorbidity. $7,9,18,19$ Similarly, patients aged above 60 years experienced more RAI-induced acute and late (any grade) complications including a rare side effect of nasolacrimal duct obstruction, which we have previously reported. ${ }^{20} \mathrm{~A}$ possible explanation could be the use of a fixed empiric dosing strategy (100-200 mCi) for RAI in our department. For the elderly age group, dosimetry-guided RAI therapy may be helpful. However, further studies are warranted. ${ }^{21}$

In contrast to previously published studies, our elderly patients experienced more all-site recurrences and had lower
10 -year DFS rate $(70.8 \%)$ even after extensive treatment that warrants more molecular-level studies., ${ }^{4,5}$

Large sample size of study population and comparison of different clinicopathological characteristics and outcomes of elderly patients aged between 46 and 60 years were primary strengths of our study. However, the study might be criticized for 1) not evaluating thyroid-stimulating hormone (TSH) suppression therapy-related complications (including osteoporosis), as TSH suppression therapy can theoretically increase the risk of osteoporosis, ${ }^{22}$ and 2) not having molecular-level data on elderly DTC.

\section{Conclusion}

In conclusion, the frequency and clinicopathological features of DTC in Saudi elderly patients are similar to published data; however, some discrepancies (no difference in regard to tumor size between patients aged below 60 years and 60 years) were seen. Furthermore, elderly patients experienced more treatment-related complications when compared to patients aged $<60$ years. Despite extensive treatment by thyroidectomy, neck dissection, RAI ablation, and TSH suppression therapy, a large proportion of elderly patients developed all-site recurrences. Large multi-institutional studies are warranted to suggest optimal treatment approaches for DTC in elderly patients. Furthermore, interdisciplinary tumor board meetings and competent follow-up of patients can minimize the disease- or treatment-related morbidities.

\section{Disclosure}

The authors report no conflicts of interest in this work.

\section{References}

1. Jemal A, Siegel R, Ward E, Hao Y, Xu J, Thun MJ. Cancer statistics, 2009. CA Cancer J Clin. 2009;59(4):225-249.

2. Hussain F, Iqbal S, Mehmood A, Bazarbashi S, ElHassan T, Chaudhri N Incidence of thyroid cancer in the Kingdom of Saudi Arabia, 2000-2010. Hematol Oncol Stem Cell Ther. 2013;6(2):58-64.

3. Bischoff LA, Curry J, Ahmed I, Pribitkin E, Miller JL. Is above age 45 appropriate for upstaging well-differentiated papillary thyroid cancer? Endocr Pract. 2013;19(6):995-997.

4. Calò PG, Medas F, Loi G, Erdas E, Pisano G, Nicolosi A. Differentiated thyroid cancer in the elderly: our experience. Int J Surg. 2014;12(Suppl 2): S140-S143

5. Hollenbeak CS, Boltz MM, Schaefer EW, Saunders BD, Goldenberg D. Recurrence of differentiated thyroid cancer in the elderly. Eur J Endocrinol. 2013;168(4):549-556.

6. Papaleontiou M, Haymart MR. Approach to and treatment of thyroid disorders in the elderly. Med Clin North Am. 2012;96(2):297-310.

7. Mekel M, Stephen AE, Gaz RD, Perry ZH, Hodin RA, Parangi S. Thyroid surgery in octogenarians is associated with higher complication rates. Surgery. 2009;146(5):913-921.

8. Seybt MW, Khichi S, Terris DJ. Geriatric thyroidectomy: safety of thyroid surgery in an aging population. Arch Otolaryngol Head Neck Surg. 2009;135(10):1041-1044. 
9. Nixon IJ, Kuk D, Wreesmann V, et al. Defining a valid age cutoff in staging of well-differentiated thyroid cancer. Ann Surg Oncol. 2016;23(2): 410-415.

10. Passler C, Avanessian R, Kaczirek K, Prager G, Scheuba C, Niederle B. Thyroid surgery in the geriatric patient. Arch Surg. 2002;137(11): 1243-1248.

11. Raffaelli M, Bellantone R, Princi P, et al. Surgical treatment of thyroid diseases in elderly patients. Am J Surg. 2010;200(4):467-472.

12. Saudi Arabia, Ministry of Economy and Planning, Saudi Arabia Population Census 2004. Available from http://www.cdsi.gov.sa. Accessed May 17, 2016.

13. Gervasi R, Orlando G, Lerose MA, et al. Thyroid surgery in geriatric patients: a literature review. BMC Surg. 2012;12(Suppl 1):S16.

14. Park HS, Roman SA, Sosa JA. Treatment patterns of aging Americans with differentiated thyroid cancer. Cancer. 2010;116(1):20-30.

15. Toniato A, Bernardi C, Piotto A, Rubello D, Pelizzo MR. Features of papillary thyroid carcinoma in patients older than 75 years. Updates Surg. 2011;63(2):115-118.

16. Amato B, Compagna R, Sivero L, Rocca A, Donisi M. Lymphectomy for elderly in thyroid surgery. Chirurgia (Turin). 2013;26(4):303-306.
17. Tartaglia F, Russo G, Sgueglia M, et al. Total thyroidectomy in geriatric patients: a retrospective study. Int J Surg. 2014;12(Suppl 2): S33-S36.

18. Ng SH, Wong KP, Lang BH. Thyroid surgery for elderly patients: are they at increased operative risks? J Thyroid Res. 2012;2012:946276.

19. Garg A, Chopra S, Ballal S, Soundararajan R, Bal CS. Differentiated thyroid cancer in patients over 60 years of age at presentation: a retrospective study of 438 patients. J Geriatr Oncol. 2015;6(1):29-37.

20. Al-Qahtani KH, Al Asiri M, Tunio MA, et al. Nasolacrimal duct obstruction following radioactive iodine 131 therapy in differentiated thyroid cancers: review of 19 cases. Clin Ophthalmol. 2014;8:2479-2484.

21. Tuttle RM, Leboeuf R, Robbins RJ, et al. Empiric radioactive iodine dosing regimens frequently exceed maximum tolerated activity levels in elderly patients with thyroid cancer. J Nucl Med. 2006;47(10): 1587-1591.

22. Ko YJ, Kim JY, Lee J, et al. Levothyroxine dose and fracture risk according to the osteoporosis status in elderly women. J Prev Med Public Health. 2014;47(1):36-46.
Clinical Interventions in Aging

\section{Publish your work in this journal}

Clinical Interventions in Aging is an international, peer-reviewed journal focusing on evidence-based reports on the value or lack thereof of treatments intended to prevent or delay the onset of maladaptive correlates of aging in human beings. This journal is indexed on PubMed Central, MedLine,

\section{Dovepress}

CAS, Scopus and the Elsevier Bibliographic databases. The manuscript management system is completely online and includes a very quick and fair peer-review system, which is all easy to use. Visit http://www.dovepress. com/testimonials.php to read real quotes from published authors. 